\title{
The Role of Monetary Policy Uncertainty in Corporate Decisions
}

\author{
Necati Tekatli \\ Kutztown University of Pennsylvania
}

The paper emphasizes the role of monetary policy uncertainty in understanding the common dynamics in corporate behavior. Building on common statistical properties of the corporate events, we extract the common pattern (factor) and the common variance (volatility) from five corporate event waves. Using the extracted common factor and the common volatility, this study examines the effect of monetary policy uncertainty on corporate decisions. We hypothesize and explore this explanation of how commonalities between the corporate event waves are formed. The Fed's actions can result in higher monetary policy uncertainty, which can increase the uncertainty about the outcomes of the major firm activities. The findings from the econometric analyses suggest that monetary policy uncertainty has a significant influence on the dynamics of corporate event waves.

Keywords: corporate events, economic policy uncertainty, factor analysis, Bayesian estimation

\section{INTRODUCTION}

Economics literature has analyzed extensively the effects of business cycles and monetary policy on firms (see, among others, Kiyotaki and Moore, 1997; Bernanke and Gertler, 1989; Gertler and Gilchrist, 1994; Korajczyk and Levy, 2003). Similarly, the corporate events literature in finance is a well developed field (see Eisfeld and Rampini, 2006; Rhodes-Kropf and Vishwanathan, 2005; Shleifer and Vishny, 2003; Harford, 2005; Rau and Stouraitis 2011). So, it is surprising that we still do not know the answers to the questions such as: "What causes common dynamics in corporate events' time-series?", "Does monetary policy or policy uncertainty cause strong comovements in the time series of independent corporate events?", "How much of a given corporate event can be explained by an aggregate economic or financial factor?" or "Does monetary policy uncertainty predict corporate dynamics?" This study attempts to answer such questions, and in doing so, it links these literatures.

We consider five corporate events, divestitures (DIV), initial public offerings (IPO), mergers and acquisitions (M\&A), stock repurchases (REP), and seasoned-equity offerings (SEO), in this study to understand the effect of monetary policy uncertainty on corporate decisions. Although these are a result of individual firms' decisions, the decision associated with each event is also likely to be affected by various common external factors, such as monetary and fiscal policies, macroeconomic conditions, industry shocks, and stock market valuations.

Each of the five aforementioned corporate events has been analyzed extensively in the literature. However, the common dynamics among these waves have been hardly studied or discussed in the literature. Several explanations in the literature have emerged as to how monetary policy could affect corporate decisions. From the neoclassical perspective, it is well known that monetary policy tightening 
hinders the GDP growth, which in turn reduces the investment opportunities of the firms. Hence, the need for IPO and SEO (see Pastor and Veronesi, 2005) is diminished, and the acquisition targets are less attractive (see Maksimovic and Phillips, 2001). However, this channel alone cannot explain why REP activities and the DIV activities are also negatively affected by the shrinking economy.

Another explanation is the market (mis)valuation. When the Fed tightens, the stock market drops, which in turn increases the cost of equity capital. Hence, capital raising activities, such as IPOs sand SEOs would suffer. M\&As activity will also be affected by this, because it also involves equity deals. DIV can be affected by this, because the segment-to-be sold is likely to be undervalued, and the selling parent would not receive a fair price for it if they choose to sell it. However, this channel does not explain why REP activities do not pick up during such periods, when the equity might be undervalued. The final group of explanation is from a cost of debt perspective. When the Fed increases interest rates, the cost of debt rises. Such an increase in the cost of debt would make firms' capital at hand more valuable, and the firms would not want to spend capital on acquisitions or repurchases. However, this channel alone does not explain why IPO and SEO activities would not increase as response to more expensive debt capital. Also, when there are external debt financing constraints, the market for divested units should pick up in order to raise capital, which is not what is observed. In the analysis, we control for these three alternative explanations.

The questions given in the first paragraph are important for policy makers and corporate man- agers. It might reveal how policymakers can influence these corporate event waves through monetary or fiscal policies. Investors can use the underlying variable(s) causing the cyclicality in the waves as a leading indicator for various investment strategies, predict the change in the cyclical component of a wave by observing the change in the underlying variable(s) that cause the cyclicality, and benefit from a rising or falling wave. Similarly, corporate managers may find it useful to know which external factors create favorable conditions for enacting certain restructuring events in their firm. They can predict the formation of such an environment by observing the changes in the underlying variable(s) that causes (or that can forecast) the rise in the corresponding wave.

This study contributes toward finding answers to the questions above by providing a detailed analysis of the role of monetary policy uncertainty in understanding the common dynamics of corporate events. First, as it is shown in Colak et al. (2021), we replicate that the time series properties of all five corporate waves are quite similar, and based on these properties, we extract the common factor and the common volatility that drive the cyclical behavior in all of the five waves. Then, conducting a detailed econometric analysis of the common factor and the common volatility, we show that the uncertainty associated with the Fed's monetary policy (as measured by Baker, et al. 2016 as the monetary policy uncertainty index) has a significant impact on the common dynamics of corporate event waves.

A brief outline of the remaining parts of the paper is as follows. Section 2. describes the data and the formation of the wave series. Section 3. reports the statistical and the time series characteristics of these waves and the extraction of the common factor and the common volatility. Section 4. explores how policy uncertainty can affect and drive the common wave dynamics. The final section provides concluding remarks.

\section{DATA ON CORPORATE EVENT WAVES}

The paper focuses on the conventional monetary policy period between 1981:M1 and 2010:M12. The term conventional monetary policy refers to a central bank altering a short-term interest rate to achieve its macroeconomic objectives. Specifically, in the United States, the Federal Reserve conducts conventional monetary policy by setting the federal funds rate to reach its legislated goals of full employment and low inflation. However, after the global financial crisis and Great Recession of 2008, central banks around the world pushed short-term interest rates to near zero, or effectively their lower limit. Unconventional monetary policy started at the end of 2008; however, the effect of conventional monetary policy tools like interest rates can last up to two years. Therefore, the data ends in 2010. 
In addition to the conventional monetary policy between the beginning of the $1980 \mathrm{~s}$ and the end of the 2000s, there are some other reasons for why the paper focuses on this time period. During those three decades, financial globalization occurred; firms' responses to policy shocks and un- certainty became more prevalent and faster due to technological developments in every aspects of communication and transmission of news; the world economies experienced stable inflation and output growth which was the so called "Great Moderation"; and this period was the era of explicit or implicit inflation targeting in global monetary policy.

In this paper, we use five different corporate event samples to study corporate event common dynamics: the first sample consists of firms that went through a divestiture event (DIVs), the second sample constitutes of firms that underwent initial public offering (IPOs), the third event sample is comprised of firms that engaged in Mergers \& Acquisitions (MAs), fourth sample covers firms that repurchased their stock (REPs), and the last event sample includes firms that issued seasoned equity offerings (SEOs). Data on DIVs, IPOs, MAs, REPs and SEOs are obtained from Security Data Corporation's (SDC's) database while IPOs are from both the SDC's database and Jay Ritter's hand collected data.

We choose those five event waves, because we believe they are the most commonly observed corporate events, and they are the most widely analyzed in the literature. If the event is a policy and not a specific action (such as capital structure choice), its wave is not considered. Another criteria applied in the selection of the wave is that the event has to be at management's discretion. The corporate actions considered must be initiated by the management and can be changed fairly quickly as a response to changing economic environment and policies.

\section{STATISTICAL PROPERTIES AND THE COMMON DYNAMICS}

This section starts with the discussion of the statistical properties of the five corporate waves. Then, based on the common statistical properties, the latent factor model used to derive the common wave dynamics is defined. Most of the findings in this section are from our previous paper Colak et al. (2021). Further details of the statistical properties and the factor model discussed in this section can be found in that paper.

\section{Time-Series Properties}

Table 1 reports the summary statistics of the corporate events data. The sample statistics such as minimum, median, maximum, mean, standard deviation, skewness, kurtosis, number of observations, and the $p$-values from a normality test (Anderson-Darling normality test) are displayed in Panel A. The DIV, IPO, REP, and SEO monthly volume numbers are highly non-normal. The M\&A wave's distribution is close to being normal. Another important observation from these figures, is the differences in variations in each wave's volume. The REP wave is the most volatile among the waves with standard deviation of monthly changes reaching 1.4089 , followed by M\&A and IPO waves with standard deviations of 1.1557 and 1.1661, respectively. The SEO and DIV waves are less volatile.

Panel A of the table presents some descriptive statistics for the DIV, IPO, M\&A, REP, and SEO waves. The wave variables measured as natural logarithm of volume levels (in year 2000 dollars) are LogVolDIV, LogVolIPO, LogVolMA, LogVolREP, and LogVolSEO. The last row of this panel shows the results (p-values) from various tests, such as the Anderson-Darling ( $\mathrm{Pr}>\mathrm{A}$-Square) test for normality of the distributions. Panel B presents the results (p-values) from the Augmented Dickey-Fuller (ADF) and Phillips-Perron (PP) unit root tests with drift, and with drift and time trend. 
TABLE 1

SUMMARY STATISTICS

\begin{tabular}{|c|c|c|c|c|c|}
\hline & DIV Wave & IPO Wave & MA Wave & REP Wave & SEO Wave \\
\hline \multicolumn{6}{|c|}{ Panel A: Basic Descriptive Statistics } \\
\hline Minimum & 17.7974 & 14.2563 & 20.2761 & 14.9643 & 16.9066 \\
\hline Median & 23.2623 & 21.0245 & 23.2701 & 22.7467 & 21.9335 \\
\hline Maximum & 25.3078 & 23.3768 & 26.1321 & 24.9392 & 24.5198 \\
\hline Mean & 23.1916 & 20.7864 & 23.2559 & 22.4677 & 21.8081 \\
\hline Std. Deviation & 0.9169 & 1.1661 & 1.1557 & 1.4089 & 1.0130 \\
\hline Skewness & -1.1998 & -1.2384 & -0.0946 & -1.3986 & -0.8861 \\
\hline Kurtosis & 4.1122 & 3.0161 & 0.3918 & 3.6507 & 1.8223 \\
\hline N of Monthly Obs. & 360 & 352 & 360 & 360 & 360 \\
\hline Normality Test & 0.0001 & 0.0001 & 0.0253 & 0.0001 & 0.0001 \\
\hline \multicolumn{6}{|l|}{ Panel B: Unit Root Tests } \\
\hline ADF w/ drift & 0.0001 & 0.0001 & 0.0001 & 0.0001 & 0.0001 \\
\hline $\mathrm{ADF} \mathrm{w} /$ drift and trend & 0.0001 & 0.0001 & 0.0001 & 0.0001 & 0.0001 \\
\hline $\mathrm{PP}$ w/ drift & 0.0001 & 0.0001 & 0.0001 & 0.0001 & 0.0001 \\
\hline $\mathrm{PP}$ w/ drift and trend & 0.0001 & 0.0001 & 0.0001 & 0.0001 & 0.0001 \\
\hline
\end{tabular}

The study next explores the autoregressive moving average (ARMA) properties of the waves. DurbinWatson tests strongly rejects the null hypothesis of no autocorrelation (for all the series the $p$-value for testing positive autocorrelation is less than $0.01 \%$ ). Further, using a combination of Box-Jenkins approach (ACF and PCF), and minimum Bayesian information criteria (MINIC) to time series modeling, we conclude that our waves are most likely to follow an ARMA process rather than an MA or an AR process.

Box-Jenkins approach indicates that both the autocorrelations and partial autocorrelations tapper off (another confirmation that we are dealing with stationary series). Autocorrelations are significant for 10 lags and higher, and the partial autocorrelations do fall below the cutoff levels after four to five lags. This is an indication that the wave series could possibly have high order AR properties. However, SCAN and ESACF approaches suggest that all of the five series are following low-order ARMA processes of the form ARMA $(1,1)$.

The paper also formally test for the presence of autoregressive conditional heteroskedasticity (ARCH) effects. To this end, Lagrange Multiplier (LM) and Portmenteau Q Tests are used. For all of the wave series the $p$-values for both LM and $\mathrm{Q}$ tests (through order 12) are less than 1\% (i.e. $p$-value $=0.0001$ ), which suggests that a very high-order ARCH model might be needed. However, as Bollerslev (1986) demonstrates, in situations where many ARCH terms are needed, a generalized autoregressive conditional heteroskedastic (GARCH) model with a small number of terms performs better. Thus, various univariate GARCH $(p, q)$ processes are fitted into the waves data. The estimation results suggest that the most appropriate volatility structure for DIV, IPO, M\&A, REP, and SEO waves is GARCH $(1,1)$.

The analysis above indicates that corporate waves have major statistical properties in common: They are all stationary, and they show similar ARMA and GARCH properties.

\section{Extracting the Common Dynamics Among Waves}

In the previous subsection, it is discussed that there is certain common statistical properties between corporate waves. Therefore, we conjecture that these commonalities are driven by specific economic and policy factors. We, first, test whether it is possible to represent the comovements between the waves with a common factor and common volatility. The test favors a one-factor model and indicated that factor analysis is an appropriate method for the comovements. 
For the particular specifications documented in the previous sections, we estimate a factor model with ARMA $(1,1)$ and GARCH $(1,1)$ properties. Given the complexity of this factor structure, the Bayesian estimation provides a more tractable and flexible estimation method than the maximum likelihood method.

The methodology used in this research involves a latent factor model of the type that is com- monly used in the asset pricing literature (see Cochrane, 1994; Campbell and Shiller, 1987 and 1988; and Serati and Amisano, 2008, among others) and in the international contagion literature (see, for example, Bekaert and Hodrick, 1992; King, et al., 1994; Dungey, et al., 2000; Forbes and Rigobon, 2002; and Bali and Cakici, 2010). The use of factor models in the corporate finance liter- ature has been limited. So, below we will show that they can be an excellent technique to analyze two or more aggregated corporate data series.

Now, we begin the description of the model with the evolution of the five waves as dynamic factor structure. In the analysis, we transform the corporate wave series by taking the logarithm of their monthly dollar volume. Let $\mathbf{w}_{t}$ be the $5 \times 1$ vector of five waves, generated by a set of $r$ unobserved common factors. Then each component of the vector of observed wave series, $\mathbf{w}_{t}$, can be written as a linear combination of these common factors:

$$
\mathbf{w}_{t}=\boldsymbol{\mu}+\Lambda \mathbf{f}_{t}+\boldsymbol{\varepsilon}_{t}
$$

where $\boldsymbol{\mu}$ is $5 \times 1$ vector of deterministic coefficients, $\boldsymbol{\Lambda}$ is $5 \times 1$ matrix of factor loadings, $\mathbf{f}_{t}$ is $1 \times 1$ vector of factors and $\varepsilon_{t}$ is $5 \times 1$ vector of idiosyncratic components.

As previously documented, the waves show strong ARMA $(1,1)$ and $\operatorname{GARCH}(1,1)$ properties. Thus, the evolution of the common factor, $\mathrm{ft}$, is governed by:

$f_{t}=b_{0}+b f_{t-1}+c e_{t-1}+e_{t}$

where roots of $|b|<1$.

Idiosyncratic factors in equation (1) are all assumed to be normally distributed:

$$
\boldsymbol{\varepsilon} \sim^{i . i . d .} N(\mathbf{0}, \mathbf{D})
$$

where $\mathbf{D}$ is diagonal matrix. However, the heteroskedastic variance properties are captured by the factor innovations. That is, the GARCH effects are defined as

$e_{t} \sim N\left(0, \sigma_{\mathrm{t}}^{2}\right)$

$\sigma_{\mathrm{t}}^{2}=\alpha_{0}+\alpha_{1} e_{\mathrm{t}}^{2}+\beta_{1} \sigma_{\mathrm{t}-1}^{2}$

where the GARCH model coefficients have to satisfy the standard GARCH conditions. Moreover, $\boldsymbol{\varepsilon}_{t}$ and $\mathbf{e}_{t}$ are mutually uncorrelated for all $t$.

The Bayesian method is used for the estimation of this factor model. The estimation method is quite cumbersome. Further details of the estimation method and the algorithm are available in Colak et al. (2021).

\section{COMMON DYNAMICS AND THE POLICY UNCERTAINTY}

In this section, we conduct a macroeconomic analysis establishing the possible role of policy uncertainty on the common dynamics of the waves. The common factor and the common variance estimated using the factor model is presented in Figure 1. There is a comovement between the factor and the volatility. Through the end of 1990s, this comovement shows a positive relationship between these two 
measures of common wave dynamics. The positive correlation started in the last years of 1990s could be due to the information and telecommunication revolution, which created the dotcom bubble in the second half of 1990s.

\section{FIGURE 1 THE COMMON FACTOR AND COMMON VOLATILITY}

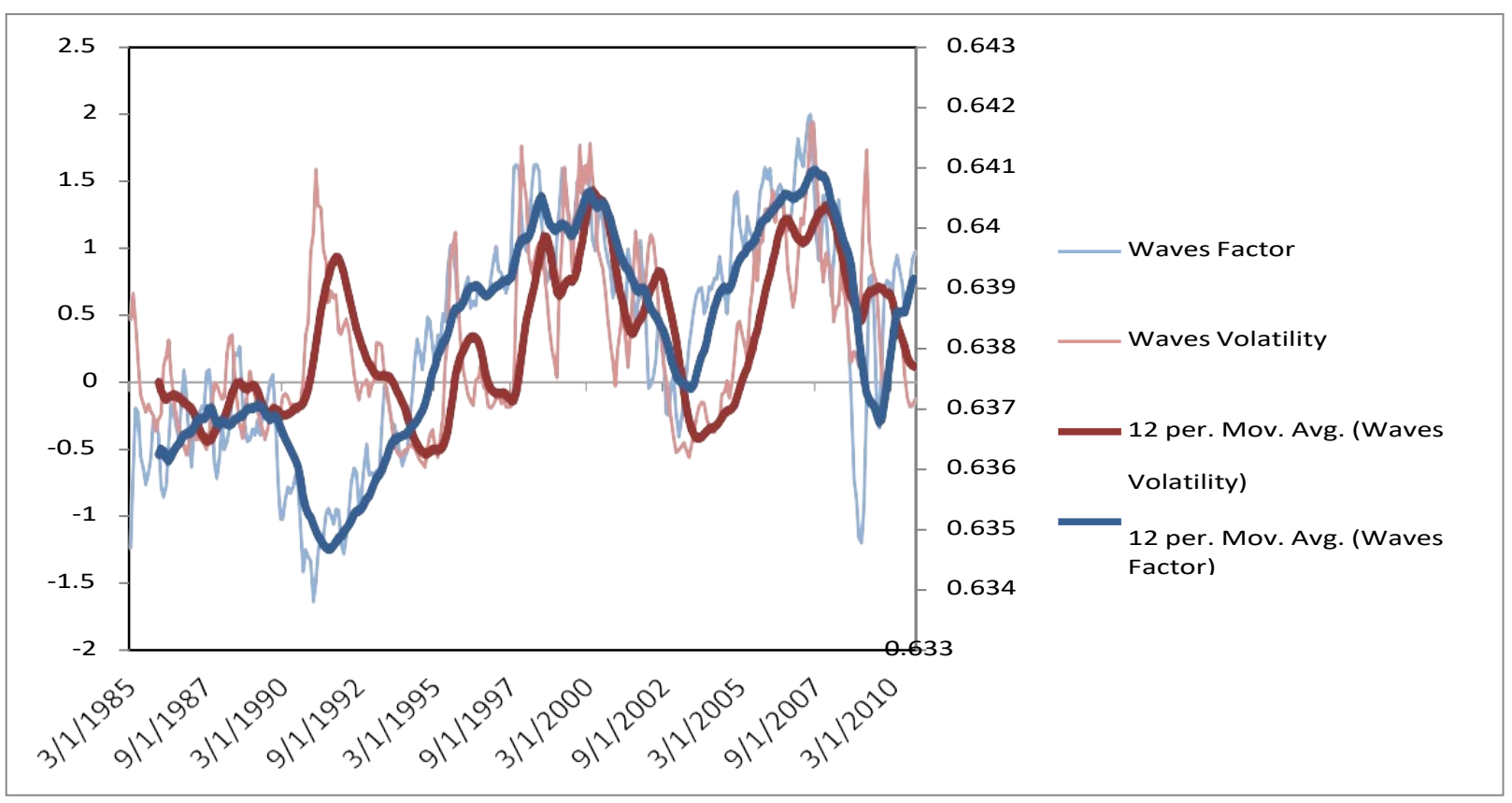

This figure plots the estimated common factor and common variance of the waves between 1985:01 and 2010:12. The time series of the corporate events are measured in aggregated dollar volume (in year 2000 dollars) per month. The considered five corporate event series are Divestitures (DIV), Initial Public Offerings (IPO), Mergers \& Acquisitions (MA), Equity Repurchases (REP), and Seasoned Equity Offerings (SEO). The factor and its GARCH variance are, first, extracted using the Bayesian methodology, and then, they are indexed for exposition purposes. The figure presents the estimated results computed with moving window of 48 months.

We first explore the relationship between the common factor (comovements among waves) and the monetary policy variables. Note that there is no prior theoretical work that tells us the direction of expected relation between the corporate events (represented by the common factor in our case) and the monetary policy variables. So, it is a matter of economic intuition and empirical analysis to explore this relationship. We use Moody's AAA bond yields, Fed Fund target rates, 3-month T-Bill rates, money supply measures and nonborrowed reserves to study this relationship. The data is retrieved from St. Louis Fed's FRED database.

We find that monetary policy related variables have high correlation coefficients. The money supply measures (M1 and M2) are highly positively correlated with the common factor: Contemporaneous correlation coefficients are +0.49 and +0.62 , correspondingly. Different measures of interest rates such as Moody's AAA bond yields, Fed Fund target rates, and 3-month T-Bill rates are significantly negatively correlated with the common factor. Their correlation coefficients are $-0.70,-0.47$, and -0.48 , respectively.

In addition to the variables listed above, we also consider another policy driven variable: the exchange rate. The value of the US dollar relative to other major currencies has a negative impact on the common factor. The correlation is -0.41 . In addition to economic developments such as trade, this number is also driven by the change in the interest rates (controlled by the Fed). When the interest rates are high, capital flows to the US are 
higher which leads to appreciation of dollar. As we showed, the correlation between interest rates and the common factor is negative and high in magnitude $(-0.70)$. The correlation between the exchange rate indicator and the long-term interest rates is +0.71 .

The results provided so far imply that the comovements among corporate waves is closely associated with the Fed's actions. Most of the variables with high correlation coefficients are either directly controlled or are targeted by the Federal Reserve's monetary policy. These findings suggest that monetary policy and the common factors are related. However, the analysis in the next sections has stronger implications than just being suggestive. The results from this analysis are widely accepted by the macroeconomics literature to have implications that are usually interpreted as indicating a form of causality. Further discussions can be found in Bernanke, et al. (2005) and Cogley and Sargent (2001, 2005).

We start our analyses with the possible transmission channel(s) of impact of the monetary policy. Then we complete the analyses with the results from the common factor and the common volatility.

\section{A Transmission Channel of the Monetary Policy: The Policy Uncertainty}

There could be several "channels of transmission" between the Fed's monetary policy and the waves' common factor. When the Fed tightens credit or does not make any policy move, this could have many intended and/or unintended consequences. Among these transmission channels, the one that has taken the most attention in the recent literature is the policy uncertainty. The monetary policy during turbulent economic periods, monetary tightening or even sometimes no-policy action can raise the policy and/or macroeconomic uncertainty in the economy. In such an environment, the firms become nervous and they avoid major corporate decisions, such as investments, equity issuances, and acquisitions (Bloom, 2009). Hence, we hypothesize that uncertain monetary policy environments or monetary policy tightening could disrupt all the corporate waves simultaneously, if they raise the uncertainty managers are facing when undertaking a major corporate action. This channel of impact seems the most plausible to us since it can explain why all the waves, even the ones that are opposite in nature such as SEOs and REPs, are positively correlated. In the following two subsections, we provide empirical results to support this hypothesis.

The best known measures of policy uncertainties are the uncertainty indices of Baker, et al. (2016). These indices are calculated in a somewhat complex way, but one of the major components reflects the monetary policy uncertainty. Among these policy indices, monetary policy uncertainty index proxies for the uncertainty associated with the monetary policy, and has a high negative correlation $(-0.54)$ with the common factor. This evidence suggests that actions or no-actions of the Federal Reserve can have an influence on the waves' comovements, and the elevated uncertainty channel is one of the transmission mechanisms of the Fed's policy.

\section{Policy Uncertainty and the Common Factor}

The correlation analysis makes it clear that the policy uncertainty measure (Baker, et al., 2016 policy uncertainty index) has one of the highest correlation coefficient with the common factor (-0.54). To further analyze this correlation, in Table 2, we correlate the common factor and common volatility to monetary policy uncertainty (MPU) in different periods. The rise in the policy uncertainty is associated with a fall in the corporate waves in both periods, as waves volume decreases during high policy uncertainty times. The correlation results suggest further an economic linkage between the common factor and the policy uncertainty measure. 
TABLE 2

CROSS-CORRELATIONS

\begin{tabular}{|l|lll|}
\hline \hline $1985-2010$ Period & M. P. Uncertainty & Waves Volatility & Waves Factor \\
\hline \hline Monetary Policy Uncertainty & 1 & -0.15 & -0.54 \\
Waves Volatility & & 1 & 0.54 \\
Waves Factor & & & 1 \\
\hline
\end{tabular}

\begin{tabular}{|l|lll|}
\hline 1985-1998 Period & M. P. Uncertainty & Waves Volatility & Waves Factor \\
\hline \hline Monetary Policy Uncertainty & 1 & 0.13 & -0.65 \\
Waves Volatility & & 1 & 0.21 \\
Waves Factor & & & 1 \\
\hline \hline
\end{tabular}

\begin{tabular}{|l|lll|}
\hline 1999-2010 Period & M. P. Uncertainty & Waves Volatility & Waves Factor \\
\hline \hline Monetary Policy Uncertainty & 1 & -0.30 & -0.56 \\
Waves Volatility & & 1 & 0.62 \\
Waves Factor & & & 1 \\
\hline \hline
\end{tabular}

The table displays cross-correlations between waves factor, waves volatility and monetary policy uncertainty.

In many cases, high uncertainty in the economy can result in lower economic activity because of the stress created on the financial and economic agents. Just to illustrate the idea, corporate investments decline when there is a rise in the policy uncertainty (see Gulen and Ion 2016). Thus, as one of the primary drivers of the business cyles in the economy, the Fed's monetary policy will also be one of the major drivers of the waves' comovements as they are part of the investment component of the business cycles. As documented above, the common factor is significantly negatively related to MPU. Figure 2 in the Appendix exhibits that this negative correlation has been rising in magnitude over time, particularly in 2000s. The magnitude of the coefficients also suggests that this relationship is quite strong. The (policy) uncertainty channel should be one of the major transmission mechanisms of monetary policy.

To understand the MPU as a hypothesis for the corporate comovements and MPU's explanatory power, we conduct a simple horse race between the monetary policy uncertainty and the alternative hypotheses. Table 3 in the Appendix presents the results. Column (1) shows that for every unit increase in MPU, the common factor declines by 0.45 standardized units. When compared to the similar regressions for the business cycle measure, cost of capital measure, and the stock market index (shown in columns [2]-[4], correspondingly), MPU has a significantly high standardized coefficient. 


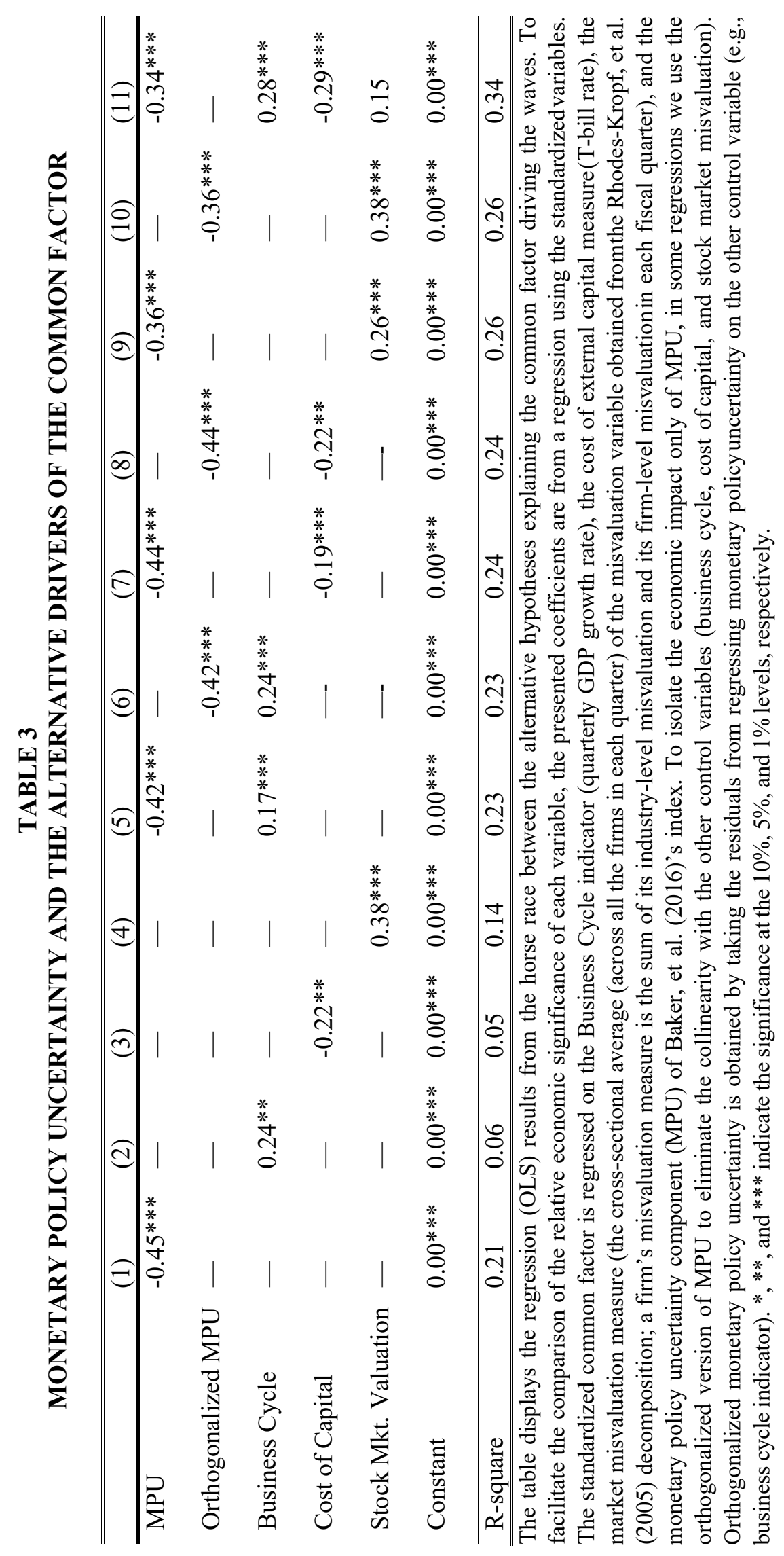

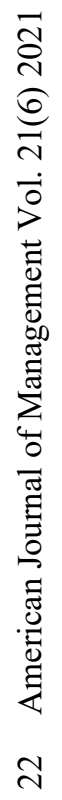


Next, we conduct a pairwise horse race between the alternative hypotheses. In column (5), we include both MPU and business cycle proxy in the same regression, and find that both of these variables have statistically significant explanatory power over the common factor, but MPU has quite a high standardized coefficient. Column (6) presents the results from the same regressions, except we orthogonalize the MPU measure with the business cycle measure to isolate the variation in MPU that are not otherwise explainable by the business cycle. The coefficient of the orthogonalized MPU is still significantly negative, suggesting that MPU has explanatory power beyond what is already reflected in the business cycle proxy. Similar type of pairwise analyses are conducted between MPU and cost of capital measure (presented under columns [7] and [8]), and between MPU and stock market index (columns [9] and [10]). Again, in all of these analyses, the policy uncertainty preserves its explanatory power.

Finally, under column (11), we present the horse race with all four hypotheses represented in the same regression: The coefficient of MPU is still significantly negative and has the highest magnitude in absolute value. Thus, we can conclude that MPU index has a major influence over the common corporate dynamics that is not explainable by the other three alternative drivers of the commonalities between the waves. The FED's monetary policy as reflected by the associated changes in the policy uncertainty seems to have a significant effect on the firms' activities. When policy uncertainty is high, firms seem to postpone conducting any major corporate event regardless of its nature. Hence, corporate events that seem opposite in nature (e.g., MAs and DIVs; SEOs and REPs, etc.) seem to peak and ebb at the same time. Elevated (subdued) policy uncertainty impedes (advances) any corporate activity, and the trough (peak) of the common factor is formed.

\section{Policy Uncertainty and the Common Volatility}

Economic policy uncertainty is also linked to the second moments of the economic dynamics, such as variances, as it can create economic and financial "volatility." In most economic instances, an uncertainty that triggers fluctuations in the economy or the financial markets also leads to volatility in the firm dynamics. Therefore, the volatility of corporate waves should also provide additional information to understand the link between corporate waves and the policy uncertainty.

Uncertainty is forward looking. Although volatility is backward looking in computational terms, it is affected through expectations channel about the possible future outcomes. Hence, uncertainty can raise the current volatility in the economy or the markets. For example, when investors are highly uncertain about future values of fundamentals, their expectations tend to react more rapidly to news, which affects variances of asset returns, interest rates and prices. From a methodological perspective, uncertainty is widely measured by some well-known statistical measures such as variance, standard deviation or interquartile range, which are commonly used as a measure of volatility. Since fundamental uncertainty does not typically resolve quickly, asset volatilities and their cross correlations become more persistent. Considering the developments affecting economic dynamics, uncertainty is definitely related to volatility in this regard.

We expect that rising uncertainty in the economy can lead to a rise in the volatility of economic activity because of the dispersion in the decisions made by the financial and economic agents. For example, stock market volatility rises during and before/after economic policy uncertainty periods (see Baker, et al., 2016) depending on the type of the uncertainty. However, after mid-1990s, the rise in the policy uncertainty is mostly associated with a fall in the volatility of the waves, since waves volume also decreases and becomes more silent during high policy uncertainty periods. Therefore, the correlation between the waves volatility and the monetary policy uncertainty has become significantly negative over time. 


\section{FIGURE 2}

\section{CORRELATION COEFFICIENTS}

\section{A: M. P. Uncertainty vs Wave Factor}

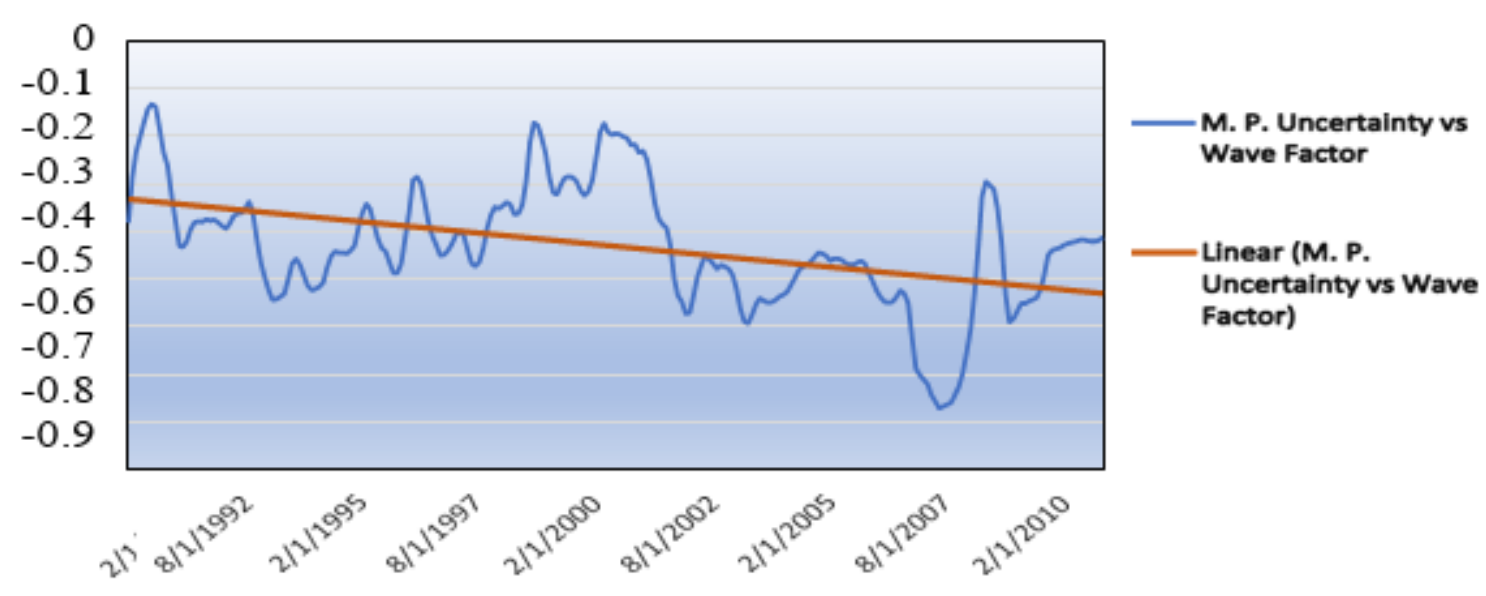

B: M. P. Uncertainty vs Wave Volatility

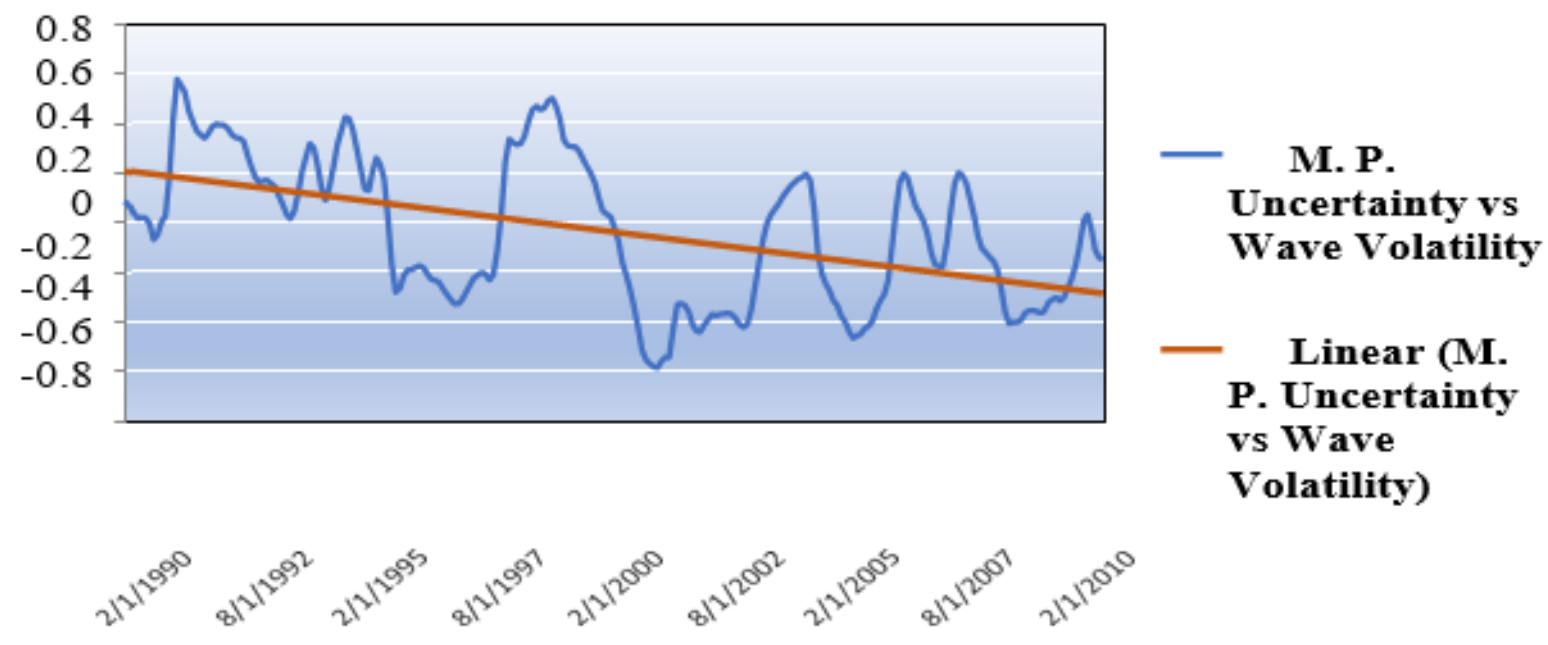

How much does the common volatility change after an increase in the monetary policy uncer- tainty? The results in 2 are computed from standardized numbers. That is, we first compute the standardized common volatility and the standardized MPU so that their mean is zero and their standard deviation is one. Using the fact that regression beta is equal to $\rho \frac{\sigma_{1}}{\sigma_{2}}$ where $\rho$ is the correlation, $\sigma_{1}$ is the standard deviation of the volatility and $\sigma_{2}$ is the standard deviation of the MPU, correlations in 2 show the change in the volatility after an increase in the MPU. Therefore, the common volatility of the corporate events can decrease by up to 0.58 standard deviation as a response to one standard deviation increase in the MPU. In the second half of the period, this response is around 0.20 standard deviation on average.

These results support the hypothesis that the MPU has adverse effects on corporate dynamics as it affects the common volatility adversely in the short- and medium-run. The wave factor is countercyclical with respect to policy uncertainty and its volatility has become countercyclical over time. 
Concludingly, high (low) uncertainty leads to less (more) volatile and more (less) silent corporate dynamics.

\section{CONCLUSION}

This study proposes a unified framework for analyzing the aggregate corporate event waves, such as DIVs, IPOs, M\&As, REPs, and SEOs. All five of these waves are positively correlated suggesting strong common driver(s). These waves do not take place in a vacuum and are part of the same economy, and thus a certain unified analysis is necessary. Hence, there should be a common factor that forms the common dynamics among the waves. To extract the common factor, we estimate a Bayesian factor analysis model.

Having this common factor in hand, we then determine which economic and/or market variables could explain the common dynamics. A more detailed analysis of the paper uncovers a major factor forming the commonalities between the five corporate waves, which is the Fed's monetary policy uncertainty. The results highlight the direct influence of the Federal Reserve on managerial deci- sion making and corporate activities. The Fed's actions or policy silence create monetary policy uncertainty, which, in turn, increases the uncertainty about the outcomes of the major firm activities. As a result, all five of the corporate event waves are hampered, and we observe lower volumes in each wave simultaneously. We hypothesize and test this explanation of how commonalities between the corporate event waves are formed. We conduct a horse race and find that the monetary policy uncertainty explanation is distinct from the alternative hypotheses explaining this commonality.

We believe that a much larger set of economic and financial variables can be considered to help uncover further channels of interactions between different economic policies and the common factor. Such research can also pinpoint which macro variables have the ability to forecast the changes in this common factor.

\section{REFERENCES}

Baker, S., Bloom, N., \& Davis, S. (2016). Measuring economic policy uncertainty. Quarterly Journal of Economics, 131, 1593-1636.

Bali, T.G., \& Cakici, N. (2010). World Market Risk, Country-Specific Risk and Expected Returns in International Stock Markets. Journal of Banking and Finance, 34, 1152-1165.

Bekaert, G., \& Hodrick, R.J. (1992). Characterizing predictable components in excess returns on equity and foreign exchange markets. Journal of Finance, 47, 467-509.

Bernanke, B., \& Gertler, M. (1989). Agency cost, net worth and business fluctuations. American Economic Review, 79, 14-31.

Bernanke, B., Boivin, J., \& Eliasz, P. (2005). Measuring monetary policy: A factor-augmented VAR approach. Quarterly Journal of Economics, 120, 387-422.

Bollerslev, T. (1986). Generalized autoregressive conditional heteroskedasticity. Journal of Econometrics, 31, 307-327.

Campbell, J., \& Shiller, R. (1987). Cointegration and tests of present value models. Journal of Political Economy, 95, 1062-1088.

Campbell, J., \& Shiller, R. (1988). Stock prices, earnings, and expected dividends. Journal of Finance, $43,661-676$.

Cochrane, J.H. (1994). Permanent and transitory components of GNP and stock prices. Quarterly Journal of Economics, 109(1), 241-265.

Cogley, T., \& Sargent, T.J. (2001). Evolving Post World War II U.S. inflation dynamics. NBER Macroeconomics Annual, 16, 331-372.

Cogley, T., \& Sargent, T.J. (2005). Drifts and volatilities: Monetary policy and outcomes in the Post WWII. U.S. Review of Economic Dynamics, 8, 262-302. 
Colak, G., Hasan, I., Tekatli, N. (2021). Comovements in Corporate Waves and the Monetary Policy. Working Paper.

Dungey, M., Martin, V.L., \& Pagan, A.R. (2000). A multivariate latent factor decomposition of international yield bond spreads. Journal of Applied Econometrics, 15, 697-715.

Eisfeldt, A.L., \& Rampini, A.A. (2006). Capital reallocation and liquidity. Journal of Monetary Economics, 53, 369-399.

Forbes, K.J., \& Rigobon, R. (2002). No contagion, only interdependence: Measuring stock market comovements. Journal of Finance, 57, 2223-61.

Gertler, M., \& Gilchrist, S.P. (1994). Monetary policy, business cycles, and the behavior of small manufacturing firms. Quarterly Journal of Economics, 109, 309-340.

Gulen, H., \& Ion, M. (2016). Policy Uncertainty and Corporate Investment. The Review of Financial Studies, 29, 523-564.

Harford, J. (2005). What drives merger waves? Journal of Financial Economics, 77, 529-560.

King, M.A., Sentana, E., \& Wadwhani, S. (1994). Volatility and links between national stock markets. Econometrica, 62, 901-33.

Kiyotaki, N., \& Moore, J. (1997). Credit cycles. Journal of Political Economics, 105, 211-248.

Korajczyk, R.A., \& Levy, A. (2003). Capital structure choice: Macroeconomic conditions and financial constraints. Journal of Financial Economics, 68, 75-109.

Maksimovic, V., \& Phillips, G.M. (2001). The market for corporate assets: Who engages in mergers and asset sales and are there efficiency gains? Journal of Finance, 56, 2019-2065.

Pastor, L., \& Veronesi, P. (2005). Rational IPO waves. Journal of Finance, 60, 1713-1757.

Rau, P.R., \& Stouraitis, A. (2011). Patterns in the timing of corporate waves. Journal of Financial and Quantitative Analysis, 46, 209-246.

Rhodes-Kropf, M., Robinson, D.T., \& Viswanathan, S. (2005). Valuation waves and merger activity: The empirical evidence. Journal of Financial Economics, 77, 561-603.

Serati, M., \& Amisano, G. (2008). Building composite leading indexes in a dynamic factor model framework: A new proposal. LIUC Papers in Economics, 212. Cattaneo University (LIUC).

Shleifer, A., \& Vishny, R.W. (2003). Stock market driven acquisitions. Journal of Financial Economics, $70,295-311$. 